\title{
Una Antropología de la Gratuidad: prácticas caritativas y políticas de asistencia social en la Argentina $^{1}$
}

\section{Laura Zapata LA CREENCIA EN LA GRATUIDAD}

MN/UFRJ

Cuando escuchamos palabras como "corrupción", "clientelismo", "asistencialismo", ellas nos remiten a un dominio social específico: la movilización de recursos estatales con fines públicos y su supuesta o real manipulación o apropiación ("inmoral, egoísta, incorrecta") por parte determinados grupos sociales. En la Argentina, según lo demuestran variados trabajos académicos ${ }^{2}$, uno de los sectores privilegiados donde la corrupción y el clientelismo pueden analizarse es en la ejecución de programas estatales de asistencia social: entrega de bolsones de alimentos, programas de emergencia laboral, programas de pequeños créditos, etc. La asistencia social básicamente consiste en la problematización de una determinada área social que afecta a un conjunto de personas consideradas en su calidad de ciudadanos, frente a lo cual el estado ensaya diversas respuestas (Oszlak e O'Donnell 1995). Algunas de estas respuestas constituyen "ayudas" estatales dirigidas, gratuitamente, hacia todo ciudadano que se encuentre en condiciones de pobreza o en situaciones de emergencia a las que no pueda enfrentar con sus propios recursos (catástrofes, enfermedad, abandono, muerte, etc.). Los abordajes históricos o sociológicos sobre la acción social del estado ${ }^{3}$ en la Argentina casi siempre son construidos en sentido evolutivo: comienzan con la beneficencia decimonónica, explican el pasaje hacia la formación y consolidación del estado de bienestar y ubican su corolario en la actual crisis neoliberal de los '90. Esta historia estatalista de la asistencia social reifica la propia noción de estado y generalmente ignora la perspectiva de los actores sociales que constribuyen a forjar los contextos en que se desenvuelven. Aquí propongo 
las prácticas de los actores. Espero con esta alternativa mostrar cómo problematizar a la pobreza y dar respuestas institucionales a ella, constituyó uno de los aspectos por medio de los cuales el estado-nación argentino se proclamó como autoridad legítima, en abierta oposición a la tradicional beneficencia de la Iglesia católica. Para ello desarrolló desde el siglo XIX vastos cuerpos jurídicos, instituciones especializadas y profesiones, especialmente los "asistentes sociales", tendientes a planificar, medir, evaluar y producir, entre otras políticas públicas, la asistencia social gratuitamente prestada a los ciudadanos que la requirieran.

La asistencia social del estado, sea en el modelo de "bienestar" o el "neoliberal", adolesce de problemas recurrentes y, según los analistas, de difícil resolución. Si las cosas gratuitas (alimentos, planes de trabajo, medicamentos, subsidios, créditos, viviendas, etc.) que supone la asistencia social son utilizadas, por parte de sus intermediarios, con fines partidarios o personalistas, eso no es asistencia sino "asistencialismo" o "clientelismo". Es decir, constituyen formas "corruptas" e inmorales de concentrar poder por medio de bienes estatales concebidos como gratuitos. Según lo muestra la bibliografía dedicada al tema: desde el propio establecimiento de este tipo de acción estatal, se ha constituido en un serio problema político y académico distinguir la asistencia genuina del asistencialismo y establecer las causas, cuando no los culpables, que propician la manipulación interesada de cosas estatalmente marcadas como gratuitas.

Íntimamente relacionado al modelo de asistencia social, la caridad cristiana privilegia la acción católica dirigida preferencialmente hacia los sectores denominados "pobres", "necesitados" o "carenciados", y propone como modelo de relación al amor gratuito, no interesado, brindado al prójimo (Pigna 1983:313-314). Esta virtud teologal es cultivada en la persona de un grupo específico al interior del Iglesia católica: el voluntariado de Caritas, organización social de la Iglesia dedicada al cultivo de aquella virtud. "Dar sin esperar nada a cambio" no es una virtud que se desarrolle espontáneamente. La caridad de una voluntaria es una propiedad expresamente cultivada y perfeccionada. Como suelen explicarles los sacerdotes a las voluntarias: si la caridad no es gratuita y desinteresada, si ella busca recompensas en el beneficiado, lo que allí en verdad se generan son "lazos de dependencia" y no la ansiada "promoción liberadora" de los pobres. Es por eso que el carácter genuino y legítimo de la caridad de la voluntaria es puesto permanentemente en duda y sometido a controles y auto-constricciones estrictas. Según un sacerdote ligado a Caritas en Argentina a diferencia de los "políticos" -que usan en su provecho a los carenciados y a los programas estatales destinados a ellos- y del estado -que recurre al "asistencialismo"-, Caritas debe ser "la mano que acaricia a los pobres". "En Caritas ¿sirvo o me sirvo?", suele preguntarle a las voluntarias el sacerdote.

Ahora bien. Siendo que estos "problemas" de la caridad y la asistencia social han sido referidos de manera tan recurrente como endémica, cabe preguntarse: ¿es que acaso los bienes gratuitos y los gestos desinteresados son posibles? La formulación de esta pregunta es desafiante pero a la vez es engañosa pues invita a buscar la 
"real", "verdadera" y "absoluta" gratuidad y generosidad. Propongo más bien adoptar una vía interpretativa, estableciendo cómo son construidas y qué sentidos son cifrados en las categorías gratuidad y desinterés por los grupos de agentes que recurren a ellas para explicar sus prácticas. Esta vía supone dos cuestiones: 1) analizar las relaciones sociales que se construyen y que hacen posible la circulación de bienes estatales gratuitos y 2) analizar los diversos sentidos que tienen esas relaciones y esas cosas marcadas como gratuitas. Si seguimos esta alternativa es probable que categorías como gratuidad, corrupción, asistencialismo signifiquen cosas bien diferentes; es probable que dependiendo de la posición que ocupen los agentes en las redes de relaciones, a través de las cuales esas cosas circulan, los significados de esas categorías varíen. ¿Cuáles podrían ser los sentidos que organizan esa variabilidad?

La caridad y la asistencia social del estado -de donde provienen la mayor parte de los bienes gratuitos que las voluntarias distribuyen- fundan su existencia en algunas creencias firmemente sostenidas y difícilmente puestas en duda. Esas creencias sostienen que existen actos gratuitos y desinteresados, los cuales se distinguen de los actos interesados que demandan una retribución, y que el flujo gratuito de bienes es un valor positivo y aún imprescindible para la sociedad. Según estas creencias se establece una profunda división entre un dominio "económico" en sentido estricto ${ }^{5}$, interesado, y otro exclusivamente moral y gratuito.

El voluntariado de Caritas y el establecimiento de políticas de estado en materia de asistencia social, deben su existencia a la creencia de que los hechos gratuitos y desinteresados son posibles; además se deben a la creencia de que la significación de estos actos es unívoca para la humanidad, y por lo tanto para diversas sociedades y aún para los diferentes grupos que componen un determinado orden social. Estas creencias suponen tomar como evidente una escisión particular, histórica y culturalmente producida por las sociedades modernas. Se trata de la cesura occidental que pretende imponer como obvia la distinción económica de dos universos sociales: en uno la economía se asocia a términos como precio, lucro, interés individual, dinero, cálculo racional, competencia, contrato; en el otro se exalta el flujo gratuito de bienes siguiendo la lógica del don, la que reprime entre sus protagonistas la apropiación interesada de cosas consideradas gratuitas, excluye la recompensa y la competencia, estimula la obligación moral y el cultivo de determinadas virtudes como la caridad y/o la solidaridad, la emotividad, la gratuidad y el sacrificio del interés propio (Mauss 1979; Sahlins 1983; Douglas 1990; Bourdieu 1996).

Sin embargo, esta división no es universal ni en su existencia ni en su significación; más aún, puede ser objeto de enfrentamientos entre los diversos grupos de una misma sociedad. Los recurrentes cuestionamientos de que son objeto tanto la caridad como la asistencia social, que se pretende gratuita, prueban la particularidad cultural y la conflictividad política de esta cesura. 
Es esa pretendida oposición categórica entre interés/desinterés y gratuidad/lucro la que genera alrededor de la asistencia social y de la caridad- aunque cada una sigue sus peculiaridades de sentido- la carga de ambigüedades, esa "doble verdad" que preña de "mentira social" y de "formalismo" a los actos generosos y gratuitos (Mauss 1979). Precisamente debido a las luchas por imponer un sentido a esta cesura particular, todo acto que se pretenda generoso corre el riesgo de ser catalogado (o des-calificado) de mentiroso, forzado, figurado e interesado. Es que las ambigüedades del don se introducen en la lógica de los fenómenos que aspiran a sostener aquella escisión cultural con pretensiones universalizantes. Estado argentino e Iglesia católica, vinculados a acciones basadas en la gratuidad, asistencia social y caridad, se constituyen como los dos polos de una relación tensa de oposición en este campo.

A partir del análisis del material etnográfico que presento aquí, intentaré mostrar las diversas lógicas a partir de las cuales la asistencia social y la caridad son construidas social y culturalmente por actores sociales concretos. Propongo adentrarnos en el funcionamiento práctico de los mecanismos sociales generadores de sistemas de categorías mediante los cuales los actores van recreando un campo estructurado de relaciones sociales, marcados por procesos de dominación que le son concomitantes. Los datos empíricos que muestran estas dimensiones conflictivas de la caridad y la asistencia social, provienen del material etnográfico producido durante seis meses de trabajo de campo que realicé en el año 2001 en Caritas de una parroquia católica argentina. Durante aquél tiempo, las voluntarias, unas 30 mujeres de entre 40 y 65 años, entendieron que para conocerlas debía compartir sus tareas, por lo tanto asumieron respecto de mí el papel de maestras de la caridad enseñándome cómo actúan, piensan y sienten esa dimensión de su vida; en tanto que yo asumí el papel de aprendiz maleable, dispuesta a aprehender acerca de voluntarias, asistentes sociales y beneficiarios de programas sociales del estado.

\section{LA GRATUIDAD COMO CAMPO SOCIAL DIFERENCIADO}

Los grupos de voluntariado hacen gala de la ausencia de jerarquías y distinciones entre sus miembros; las posiciones de responsabilidad y autoridad son minimizadas en su valor o ridiculizadas con ironía. La única jerarquía abiertamente aceptada por estas mujeres es la del sacerdote, una persona que por su condición de género se constituye en administrador de los bienes sagrados de su credo, y que en Caritas dirige y forma espiritualmente a las voluntarias. No obstante, esta posición jerárquica es sumamente conflictiva y produce intensas aunque sutiles resistencias por parte de las mujeres ${ }^{6}$. Pese a la afirmación igualitaria, varias gradaciones de voluntariado forman una organización social diferenciada, delicadamente equilibrada. Esa organización social se expresa en una dimensión política, una 
ordenación jerárquica de status y capacidad de mando; así como se expresa en una forma de economía, una pautada manera de definir y apropiarse legítimamente de determinados bienes, materiales y simbólicos. Así, "directora", "voluntarias" y "chicas" forman algunas de las designaciones que adopta esa economía y política del voluntariado. Las asistentes sociales, llamadas por las voluntarias "licenciadas", forman parte de esta organización.

Directora, en Caritas, es sólo una de las mujeres. Susana, quién ejercía tal cargo durante mi paso por esa institución, me decía acerca de su lugar:

Yo soy de las reuniones, no sé, soy a la que le dan un poco más de bolilla, la que dice las ideas, que las elaboramos. [sonriendo dice] Ellas dicen la mandamás, la dueña de casa. Pero, [ahora, seria] todos somos los que manejamos ahí.

Susana, una mujer de cincuenta años nacida en la ciudad donde reside, estudió en una tradicional escuela católica. Su esposo era empleado municipal, sus dos hijas estaban terminando sus carreras terciarias y universitarias. Su especialidad era la fotografía y además cosía en su casa para fábricas de ropa local. Asistía a misa regularmente y desde fines de la década del ochenta, junto a un grupo de feligresas, reunían alimentos entre los comerciantes del barrio y los entregaban en la capilla a las familias necesitadas. Susana enmarcaba estas acciones en la virtud cristiana que cultiva en su persona: la caridad. Desde los doce años militó [participó] en Acción Católica. La biografía de Susana, comprometida moralmente con la comunidad ${ }^{7}$ parroquial local, la habría tornado en una especialista en la conducción de grupos de católicos, cuya trayectoria sería respaldada y reconocida por miembros de otras comunidades de la ciudad.

En los relatos biográficos de Susana, además de la comunidad, son su padre y, especialmente, su madre, las personas que fundamentaban el conjunto de virtudes y saberes ligados a su persona. Con este conjunto de atributos la directora construía el fundamento que legitimaba sus títulos y cargos:

Esta vocación la aprendí en mi casa, uno no puede dar lo que no aprendió. En Acción Católica aprendí estos valores. Mis padres siempre están presentes en las acciones solidarias (...) Ellos visitaban familias, atendían a vecinos enfermos, siempre preocupados por los otros.

No se trata entonces de un individuo que cultiva una virtud en su persona o que asume un status circunscripto a una tarea y saber objetivo, la directora representa, en sus acciones generosas, a grupos sociales que se materializan en su persona: una comunidad católica y una unidad social de origen basada en el parentesco, su familia. Representan además un saber práctico depositado -en la forma de herencia- en sus personas: ellas saben ayudar (dar), y lo hacen con desinterés y gratuidad. 
El mayor prestigio de Susana residía en los 700 socios de Caritas; su grupo de 30 voluntarias; la unidad, igualdad y generosidad de este grupo; el edificio propio de Caritas Ilamado "la casita"; las más de 200 familias a las que las voluntarias ayudaban en el barrio. Estos recursos constituyen la base de legitimidad de su título de directora, vivido como un rango honorífico y una forma de reconocimiento social que consagra tanto las virtudes y saberes adheridos a su persona como las relaciones sociales que ella es capaz de articular.

Este reconocimiento de que son objeto las directoras no tienen su escenario entre las voluntarias, donde no hay lugar para títulos, sino en las reuniones a las que asiste en su condición de "autoridad". Ir a esas reuniones es la tarea de una directora. Reuniones tales como: la organización de la "Colecta Anual de Caritas" y encuentros con las asistentes sociales de los programas estatales que Caritas administra. En estas reuniones directoras y licenciadas evalúan los programas, comparan los listados de beneficiarios, discuten criterios de inclusión y exclusión de beneficiarios y los modos de trato con esos grupos. En estas oportunidades su Caritas, sus comunidades, sus virtudes, se tornaban en recursos que sostenían sus títulos honoríficos y las jerarquías concomitantes.

Por medio de estos rasgos las directoras se hacen de los fundamentos necesarios para participar de un delicado campo, constituido entre otros por agentes estatales y agentes eclesiales y laicos de la Iglesia Católica. En este campo se juega un capital simbólico por excelencia: la administración de programas de asistencia estatal y, en consecuencia, la capacidad legítima de intervenir en la definición (producción) de los grupos sociales pasibles de ser asistidos por medio de recursos estatales. Universo social que reclama para sí desde mediados de la década del cuarenta, de manera exclusiva y con relativo éxito ${ }^{8}$, el estado argentino y un grupo de funcionarios especializados que crecieron con él, las asistentes sociales.

En este mundo particular circulan saberes, técnicas, formas legales y administrativas (papeles, reglamentos, planillas, expedientes, firmas, sellos), formas de jerarquía y autoridad (títulos que ameritan fórmulas de cortesía y expresiones de respeto), cuerpos de ideas basadas en la forma que debe asumir la ayuda social y cosas o bienes materiales, comida, dinero, que objetiva la ayuda estatal y caritativa. Una vez admitidas en este espacio de juego, las directoras acceden a cajas de alimentos, créditos estatales y programas de empleo subsidiado. Se trata de una esfera de intercambio en la que fluyen cosas materiales. Del control y acceso privilegiado a ellas se desprenden elementos prestigiosos y prestigiantes para las voluntarias: formas de reconocimiento, de honra, de prestigio, de poder. Bienes simbólicos que reciben el nombre de ayuda, asistencia o promoción, y sus valores oscilan entre la profesionalidad, la gratuidad y el desinterés, asociados a la condición de género que predomina en los agentes legitimados para administrarlos. Se trata de un mundo cuya regla de oro es la eliminación (al menos aparente) del interés individual; que precisa de agentes sociales orientados a los valores simbólicos que lo constituyen, a la clase de recompensas poderosas que distribuye: reconocimiento, formas de autoridad y modos de dominación simbólica. 
Este campo también está constituido por los funcionarios especializados del estado, las asistentes sociales, profesionales expertos en la atención de "problemas sociales". A diferencia de las voluntarias, su identidad no se estructura en base a un conjunto de emociones o virtudes sino, justamente, en su opuesto: un cuerpo de saberes objetivos sintetizados en títulos universitarios o terciarios, y en empleos estatales -remunerados. Los diplomas y funciones laborales ligadas a los programas de asistencia estatal, legitiman su posición en el tratamiento de los “problemas sociales".

Las voluntarias, con ironía y respeto, las/los Ilaman las/los licenciadas/osª . Ironía pues, tal como me decía la voluntaria Daniela, en cuestiones de ayuda a los necesitados “más aprende uno haciendo, viendo las cosas todos los días" que asistiendo a cursos en los que "aprendimos algunas cosas ... pero si me decís qué me quedó, te digo que nada". Respeto pues, las licenciadas con sus ropas más finas que las de las voluntarias, las carpetas, agendas y planillas que portan, los sellos profesionales con los que acompañan sus firmas, su vocabulario densamente poblado de palabras y conceptos desconocidos para las mujeres de Caritas, despiertan su admiración. Esos atributos de las licenciadas las hacen depositarias de un tipo de saber diferente y un tipo de autoridad ligada a la esfera del estado, que las voluntarias reconocen y del que se esfuerzan por distinguir. A la vez las voluntarias no son "especialistas", son personas virtuosas y, por eso, se consideran más fieles y directamente entregadas a la ayuda y a los necesitados.

Las licenciadas tienen lo suyo para enseñarle a las voluntarias y éstas, aunque porten sus títulos de directoras, están en esas reuniones para aprender procedimientos burocráticos, así como las "maneras" indispensables, basadas en la delicadeza y el respeto, para entablar una relación de confianza y conocimiento mutuo con las licenciadas, lo cual les permite a las voluntarias acceder a la administración de los programas de asistencia social. Esas reuniones son instancias donde van forjándose dos cuerpos de agentes sociales, las licenciadas y las voluntarias, a la vez que son instancias de reproducción social de esos cuerpos. Licenciadas y voluntarias disputan entre si un lugar de acción dentro de esa sensible esfera de bienes, los programas de asistencia social.

Para Susana, todas las personas que asistían a estas reuniones, incluida yo misma que la acompañaba a ella en mi condición de aprendiz, eran políticos, excepto ella. Es decir, las asistentes sociales, las manzaneras y los referentes barriales, representantes de asociaciones de fomento de la ciudad, y yo "usan términos políticos que nosotros no usamos" y podrían "sacar de la pobreza y de la solidaridad un beneficio para ellos". Los términos políticos son, para Susana, maneras abiertas de enfrentamiento. Además, a través de los programas estatales, las licenciadas y todos los otros agentes podrían "caer en la tentación" de extraer ese "beneficio" que habita en la pobreza y en la solidaridad, usarlos "políticamente" (en beneficio propio); Susana, en cambio, se halla inhibida, moralmente, del "beneficio" que vive en los programas estatales, porque lo suyo es la virtud, la gratuidad y la caridad", no la 
"política"12. Aquí radican, en parte, los significados y el fundamento de la legitimidad de que es objeto la directora en los encuentros que mantiene con las asistentes sociales. El desinterés y la gratuidad constituyen su base moral; el respeto y el recato frente al orden jerárquico que ocupan las licenciadas y los sacerdotes, constituyen una forma de representación del mapa social en el cual opera.

Para las licenciadas lo que las voluntarias hacen con los pobres es apenas "asistencialismo". Lo único que saben es "darle y darle a la gente pobre, nunca enseñarles a hacer cosas, a ganarse los alimentos por ellos mismos o a saber sus derechos. Así siempre van a ser pobres y depender de su ayuda", como me explicaba una estudiante universitaria de Trabajo Social. En cambio, los profesionales de lo social se proponen metas más amplias y penetrantes: "promover" entre los pobres formas de desarrollo o progreso que transforme sus hábitos y su mentalidad y, con ello, su lugar en la sociedad (Alayón 1980). Es aquí donde la disciplina Trabajo Social se reconoce no sólo como una técnica al servicio del estado, sino como un proyecto que pretende "transformar" la sociedad, y en ella especialmente a su costado más "bárbaro", "atrasado" o "subdesarrollado": los pobres. Las voluntarias son apenas "personas voluntariosas", "gente de buenos sentimientos", pero incapaces de desarrollar un cuerpo de saberes abarcadores, basados en la idea de la promoción presentes en la disciplina de Trabajo Social. Mientras que el asistencialismo generaría dependencia que coartaría la libertad y la igualdad de las personas, la promoción estimula su autonomía, desarrollo y progreso, haciendo especial hincapié en la noción de "persona" frecuentemente entendida como la de "ciudadano" liberal (individuo).

Decir que su trabajo constituye una forma de asistencialismo, ofendía y degradaba a las voluntarias. Según me explicaba Daniela, "promover" o "asistir" no dependía sólo de su "buena voluntad", sino de los rasgos culturales que exhibían los necesitados:

Tenés que diferenciar entre el que es vago por naturaleza y el que realmente necesita. Entonces ahí sí hay que hacer promoción.

Asistencialismo y promoción son dos formas enfrentadas en la Argentina de concebir y organizar la "asistencia social"13. Este enfrentamiento tiene como fondo, por un lado, la profesionalización del servicio social y su institucionalización dentro de la estructura burocrática del naciente "estado benefactor", impulsado por J.D. Perón en la década del cuarenta ${ }^{14}$; por el otro, tiene como hito significativo el cierre de la Sociedad de Beneficencia en la misma época y la deslegitimación de la caridad como modo de ayuda social de las clases altas hacia los pobres $^{15}$. 


\section{LAS COSAS Y LAS PERSONAS}

Sobre este fondo histórico se ha desenvuelto en la Argentina el universo de la asistencia social formado por voluntarias, sacerdotes, asistentes sociales, beneficiarios, entre otros agentes. En este campo la principal arma de enfrentamiento es la acusación de utilizar política o interesadamente los programas estatales de asistencia gratuita. Hacer asistencialismo y usar políticamente los programas, son acusaciones que usan para descalificarse mutuamente tanto los agentes del estado como las voluntarias y los sacerdotes de Caritas. Estas acusaciones indican que la condición de gratuidad de los bienes objetos de la caridad y de la asistencia estatal, es desvirtuada. Las cosas gratuitas no debieran producir beneficio en ninguno de los intermediarios que tienen acceso a ellas, asistentes sociales, políticos, voluntarias o sacerdotes; sólo pueden beneficiar a sus "beneficiarios" ideales, los pobres. Sin embargo, el beneficio de las cosas gratuitas es difícil de controlar, puesto que la producción de ese diferencial de valor no depende tanto de las propiedades inherentes de los cosas, sino de las percepciones y de las relaciones sociales que hacen posible a esos bienes. ¿Cómo llegan a adquirir valor las cosas marcadas por su gratuidad?, ¿Si las cosas pierden su condición de gratuidad, se transforman entonces en bienes disponibles para el intercambio mercantil? Voy a mostrar estas dimensiones de las cosas a través de la descripción de la categoría social denominada "chicas" en Caritas.

Según me explicaron las voluntarias, las chicas eran personas "asistidas, gente que se quedó en Caritas después que terminaron los programas 'Trabajar'". Es decir, eran beneficiarias que a cambio de su servicio voluntario en Caritas recibían una bolsa de alimentos. La acción de pedir, con relativo éxito, en Caritas supone primero construirse como necesitado y hacerlo asumiendo una relación específica con una voluntaria ${ }^{16}$. Pero pedir y colaborar en Caritas demanda cultivar una relación que lleva tiempo y se ajusta a un código ético basado en la ayuda que presta una voluntaria y en las obligaciones a que se compromete el beneficiario ${ }^{17}$. A través de este compromiso personalizado, aunque desigual, una beneficiaria puede transformarse en una de las chicas.

Por ejemplo para Karina, una de las chicas, fue Susana quien la invitó a quedarse en Caritas como voluntaria después que terminó un programa estatal de empleo subsidiado que coordinaba la directora. Para Cecilia es Ignacia, una voluntaria, la persona que la ayuda en todo, a ella recurre cuando tiene un problema. Soledad, una voluntaria, reconoce que en Caritas "Julieta me enseñó todo lo que sé aquí, a ella le debo lo que sé". Al propio tiempo el trabajo de Soledad "es estar a cargo de las chicas". "Yo vine aquí por Soledad, ella me invitó", dice de sí Fernanda, otra de las chicas. 
Aquí opera de modo "total" esa forma de intercambio que recuerda al patronazgo, cifrado en la categoría nativa de "ayuda"18 y en la obligación moral que ella produce. Entre voluntarias y chicas la ayuda designa un esquema social -un código ético, una relación social personalizada, una forma ceremonial basada en la discreción y el respeto, un modo de categorización jerárquica y formas de reconocimiento- que posibilita el desplazamiento de determinados bienes. Esta economía y esta política, culturalmente fundada, concibe al flujo de bienes basándolos en el derecho que grupos de agentes reclaman sobre ellos. Por una parte, la economía y la política de la asistencia social tiende a basarse en dos principios contradictorios: por un lado se basa en las nociones de individuo sujeto de derechos abstractos, generalmente llamado "ciudadano", y en la circulación impersonal de bienes gratuitos, abstractamente definidos; por otro basa su existencia en el reemplazo de la idea de ciudadano por un colectivo, los pobres o necesitados que reclaman intervenciones particularizadas, no universales. Las tensiones que surgen de estos fundamentos contribuyen a producir un escenario marcado de conflictividades y enfrentamientos. En Caritas, lo que las chicas evidencian es que la asistencia social no sólo trata de las relaciones sociales que particularizan la entrega de bienes estatales, en teoría desinteresada y impersonalmente pautados, sino de las formas de dominación simbólica que producen los procesos de circulación de bienes gratuitos ${ }^{19}$.

Las voluntarias no demandan bienes tangibles como los políticos demandan votos. Orientadas hacia bienes simbólicos, su recompensa no es consciente ni plenamente buscada y calculada, la encuentran en las formas de autoridad que se inscriben en sus personas por medio de las ayudas desinteresadas, por caritativas, que prestan a las chicas. Es un modo de dominación basado en la lógica del don gratuito que liga a quiénes ayudan y a quiénes reciben agradecidos, tanto por medio de las cosas, interesadamente cambiadas, como por medio de las creencias en que se fundamenta tal intercambio -el aprecio, la confianza, la pasión, la lealtad ${ }^{20}$. Son las chicas las que consagran a las voluntarias como "grandes personas", generosas, solidarias, reconociéndose a sí mismas "obligadas", en "deuda". La ayuda y el agradecimiento describen un tipo de lazo, una obligación perdurable, abarcante, que no encuentra en un acto específico, el voto, una forma de pago: por eso las chicas suelen definirse como "eternamente agradecidas", eternamente obligadas.

La economía y la política que subyace al flujo de bienes marcados por su gratuidad, la llamada política social, define una densa red de relaciones sociales construidas a partir de imputaciones morales que ligan jerárquicamente y de manera duradera a las personas entre sí. Un orden contingente, moralmente fundamentado, y que tiene a la gratuidad como uno de los ejes constitutivos tanto de su dinámica de funcionamiento, como de su dinámica conflictiva. Una red de ayudas y agradecimientos que cimientan, en última instancia, y que penetran la propia matriz de organización del estado-nación, imponiéndole el problema de distinguir y producir una distinción universalizante 
y de orden jurídico: el mundo del lucro diferenciado del mundo de la gratuidad.

Esta distinción, en contextos empíricos, varía ampliamente su significado, transformando al mundo de la gratuidad en el mundo de los malentendidos, las dobles verdades y las ambigüedades. Las voluntarias y los sacerdotes acusan al "estado" y a los "políticos" de usar a los programas sociales en su beneficio y de practicar el asistencialismo entre los pobres. Las asistentes sociales sostienen que las voluntarias sólo saben "darle y darle cosas a la gente sin promoverlas". Los sacerdotes controlan las virtudes de su voluntariado, ellas ¿sirven o se sirven en Caritas?. Las voluntarias suelen detectar en las "chicas" y en los beneficiarios un "síndrome" de apropiación de las cosas gratuitas disponibles en Caritas. Amanda, una de las voluntarias, me explicaba este síndrome: "la gente ve tantas cosas aquí en Caritas que dice 'esto para mí, esto para mí, esto para mí'. Quieren todo". Por lo tanto, para las voluntarias, las chicas y los beneficiarios precisan de controles y formas de constricción de esa especie de egoísmo que manifiestan en relación a las cosas gratuitas que distribuye Caritas.

Pasados varios meses de mi trabajo de campo comprendí que las voluntarias, por estar ungidas por el desinterés y la gratuidad, podían darse a sí mismas determinados derechos sobre las cosas sin que ello mansillara su status de desinteresadas maestras. Pero este derecho que sobre las cosas se auto-reconocen las voluntarias, no es abiertamente dispuesto: la discreción en esta materia es la regla. Un día me di cuenta que en mi trabajo de campo nunca había acompañado a las chicas los lunes, jornada de limpieza y orden en Caritas. Así que me fui al edificio y esto es parte de lo que registré en mi cuaderno de campo ese día:

Lo primero que hice cuando llegué fue sentir que no debía estar ahí, pasé al cuaderno algunas de las visitas que había hecho y luego ayudé a las mujeres con sus tareas. (...) Cuando terminamos con la limpieza "hogareña" de Caritas, Soledad y las demás sacan cajas y bolsas del depósito y preparan bolsas de alimentos, siguiendo el mismo procedimiento que para las bolsas de los beneficiarios. Disponen montoncitos en dos mesas y van armando pilas con aceite, conservas, cajas de tomate, galletitas, fideos. Yo no me daba cuenta del sentido que tenía ese movimiento que cerraba el día. Como la hija de Soledad cebaba mates me aproximé a ella y ahí me quedé charlando con Karina. La mesa va llenándose de cosas, llega Julieta y saca más cosas del depósito para hacer crecer los pilones de mercadería. Yo descubro que presencio una nueva dimensión de la caridad, la que desconocía hasta el momento (...). Entre Fernanda, Soledad, Silvina, Julieta, Silvia y Mariana, acomodan las pilones y embolsan las cosas. Julieta agarra una bolsa para ella y Soledad le muestra un listado con nombres que no veo; en verdad no miro por miedo a que vean mi interés especial sobre esa práctica, siento culpa de asistir a esa escena que quizás ellas quisieran haberme ocultado. Soledad me pregunta si voy a llevar una bolsa, así arman un montoncito más. Respondo no gracias. Julieta prepara su bolsa en su bicicleta y salimos juntas de Caritas hacia nuestras casas. Allí quedan el resto de las mujeres preparando sus bolsas, calculando un producto para cada una, las cabezas agachadas contando cada montoncito, viendo a qué bolsa le falta qué producto. Como algunos no alcanzan para todas, a la que le falta lo reemplazan poniendo dos productos repetidos... 
Afuera de Caritas, en vez de mostrarse, como yo esperaba, "avergonzada" y darme explicaciones, aunque fueran falsas, acerca de la bolsa que se llevaba de Caritas, la voluntaria hablaba acongojada de una tema que la inquietaba. Yo la escuchaba perpleja. Los registros continúan así:

En el camino Julieta me cuenta su preocupación (que no sé dónde se origina, en qué conversaciones) acerca de que las chicas no se interesan por ir a misa o por ir a charlas, cursos sobre religión. 'Al final hay que pensar que nosotros somos iglesia y que lo que hacemos está dentro de la iglesia, no somos otra cosa. Pero a las chicas no les gusta, les nombrás algo de ir a misa o a una reunión y salen corriendo. Viste que Fernanda dice siempre que ella de misa (no quiere saber) nada, pero no es así, hay que empezar a hacer algo. La otra vez Ignacia les dio una charla sobre Caritas: viste que Ignacia sabe mucho, ella es catequista y sabe. Pero después no pasó nada'.

En lugar de hablar de las cosas que, a mi juicio, corruptamente se llevaba de Caritas, Julieta me decía que ellas, las voluntarias, eran Iglesia y que las chicas se negaban a serlo. A ser iglesia se llega por medio de la participación en misas, charlas y cursos de religión. Yo asistí varias veces a misas, celebraciones de la comunidad, retiros espirituales, caminatas, peregrinaciones, cursos de religión, y peñas en la parroquia. Es por medio de estas prácticas que se conforma una comunidad moral, basada en el mutuo reconocimiento. Las chicas se negaban a ser una sola y misma comunidad con las voluntarias. Por lo cual no participaban cabalmente de la esfera de bienes y obligaciones que aquella comunidad distribuye y demanda. Éste es uno de los medios a través de los cuales una chica podría llegar a ser considerada una verdadera voluntaria, y asumir la pauta de derecho, la apropiación legítima de determinadas cosas, la jerarquía correspondiente, basada en la virtud, y la obligación concomitante, la lealtad.

Más tarde, en otro viaje a través del barrio, Susana, la directora de Caritas, llevaba pan lactal donado a Caritas en el carrito de su bicicleta. Yo, desde la mía, miraba su bolsa de pan y la naturalidad con la cual lo había cargado. Advirtiendo mi preocupación, Susana me dijo mirándome a los ojos y con un dejo mezclado de confesión y desprecio:

Vos te pensás que porque nos llevamos pan o fideos de Caritas compensamos todo lo que nosotros dejamos ahí. Andando todo el día, para todos lados, buscando donaciones. Mirá que uno se va a fijar en el pan que una de nosotras se lleva, ah!...

Las voluntarias, a diferencia de las chicas, no estiman aquellos bienes como objetos de interés especial, no resultan cosas que las preocupen, ni medios explícitos de controlarse mutuamente. Como mi forma de categorización fue desde un principio como voluntaria, no sé que opinan las chicas sobre esas formas de apropiación y clasificación 
de bienes. Puesto que ellas también forman parte de las "cosas" que las voluntarias controlan y disponen, es probable que tengan bastante para decir. Pero a mí no me lo dijeron, quizás por mi rango y mi status. En cambio, estoy en condiciones de establecer que la apropiación personal de cosas entre las voluntarias no constituye una forma de violación a ninguna pauta por ellas distinguida. Si se hayaran presentes agentes jerárquicamente superiores a ellas (sacerdote o asistente social) o un agente no clasificiado según los principios de distinción válidos al interior de Caritas, entonces sí la apropiación de cosas materiales se tornaría un problema perceptible y reprimible. Para las voluntarias las cosas gratuitas pertenecen naturalmente a la esfera del desinterés, lo cual designa una virtud que constituye su identidad. Esto significa decir que las cosas gratuitas son una forma de extensión de sí mismas: sus cosas. Por lo tanto, ese modo personal de apropiación no tiene un nombre específico con el cual lo designen. Lejos está de ser concebida como una forma de "corrupción", de apropiación inmoral. Para ellas ésta no es una forma de "servirse"; acto inmoral del que ellas son incapaces. No obstante, para que las cosas se tornen sus cosas, es preciso tener en cuenta una operación simbólica importante basada en el cálculo con el cual Susana explica el desprecio que le amerita el pan que lleva en su bicicleta. Su "servicio", lo que ellas "dejan ahí" (en Caritas) no se "compensa" con cosas tan groseras como fideos o pan. "Ah!", esta despreciativa y desafiante interjección con que Susana remata su argumento, indica que la mirada interpretativa debe dirigirse hacia las sutilezas calculadoras, aunque no por eso plenamente conscientes e intencionadas, de las que son capaces estas mujeres.

Arjun Appadurai, retomando a Geörge Simmel, señala que una cosa se constituye en mercancía sólo cuando sobre ella los individuos reposan sus ojos deseantes y son capaces de sacrificar otro valor por adquirirlas. Los alimentos y la ropa de Caritas no son bienes especialmente deseados por las voluntarias, ésas son cosas de "chicas". Las voluntarias apetecen bienes lujuriosos ${ }^{21}$, como sugiere Werner Sombart, bienes "cuyo principal uso es retórico y social, bienes que son simplemente signos encarnados. La necesidad a la que ellos responden es fundamentalmente política" (Appadurai 1986: 38). Las voluntarias reclaman como atributos adheridos a sus personas determinadas virtudes, la caridad y saberes técnico-burocráticos, tornándolos en capitales simbólicos que las habilitan como legítimas manipuladoras de bienes definidos, estatalmente, como gratuitos. Ellas se orientan hacia los bienes ostentosos, cuya principal función es la de comunicar status y poder, es el derecho que se arrogan y que les reconoce el estado a las voluntarias para administrar (lo que constituye una forma de apropiación), por medio de programas de asistencia social, a determinadas poblaciones, los pobres.

Por medio de esos bienes las voluntarias establecen "relaciones asimétricas durables de reconocimiento (...), fundadas en el crédito concedido a la filantropía" (Bourdieu 1996:16). Estas relaciones, cuando abarcan la esfera de los programas de asistencia y a sus bienes, pueden "tornarse principio de autoridad estatal, burocrática e impersonal, a través de la redistribución burocrática que (...) no excluye completamente, por el ejercicio de la corrupción, formas de apropiación personal y de clientelismo" (Idem: 16). 
Ahora bien, conviene tener cuidado con el uso que hacemos de las categorías corrupción y clientelismo, pues ellas no tienen un significado independiente de las relaciones sociales que le dan un sentido específico. Como he mostrado hasta aquí, actos considerados por determinados sectores sociales como corrupción o asistencialismo, constituyen para otros grupos sociales, relacionalmente posicionados, modos legítimos de actuación y formas genuinas de apropiación de bienes.

Como acierta Mauss “las cosas no son inertes", ellas actúan, creando lazos morales de dependencia durable entre las personas que las dan, que las reciben y que las devuelven. Los objetos que circulan marcados por su condición de gratuidad, a través de las redes de relaciones sociales caritativas y asistenciales, son una muestra de ello. 
1 Este artículo es una reformulación de la ponencia presentada a la "V Reunión de Antropología del Mercosur (RAM)", Florianópolis, 2003, denominada "Antropología de la Gratuidad: prácticas caritativas y asistencia social en la Argentina". Agradezco los comentarios críticos que recibió este texto en esa oportunidad. El texto se vio beneficiado, además, por las sugerentes observaciones que realizó Fernando Rabozzi. Los datos etnográficos y el tratamiento conceptual que reciben son más extensamente desarrollados en mi tesis de Maestría en Antropología Social.

2 Entre otros autores: Golbert, 1992; Grassi, 1996; Masson, 1999; Rodríguez, 2001; Auyero, 2001

3 Passanante, 1987; Isuani, 1990; Lo Vuolo, et. al., 1999.

4 Ver esta perspectiva en Alayón, 1989; Lumi, Golbert y Tenti, 1992; Lo Vuolo y Barbeito, 1998; Auyero, 2001; Grassi, 1996; Isuani, 1992.

6 Para Bourdieu la economía en sentido restricto alude a la economía formal aquella que prevé que todo acto económico está guiado por nociones como cálculo racional que busca el máximo beneficio entre fines alternativos y recursos pre-definidos como escasos (1996).

7 Descripciones sobre la forma en la que esa relación social con el sacerdote es construida por las voluntarias, las desarrollo como parte de mi tesis de maestría, ver Zapata (2003).

8 Comunidad es una palabra nativa que alude a una corporación moral con la cual los fieles católicos se representan como una totalidad homogénea y así se comunican entre ellos y se identifican hacia fuera del grupo de feligreses. En este trabajo no asumo su existencia empírica, en cambio le reconozco significación desde el punto de vista de las mujeres católicas, los profesionales, los sacerdotes y los beneficiarios que atraviesan el universo de Caritas.

9 Esta reivindicación del estado-nación no estuvo ajena de abiertos enfrentamientos entre diversos sectores en Argentina. Recalde (1991) destaca las luchas que por la estatización de la asistencia pública entabló en el país, en las tres primeras décadas del siglo XX, un grupo de médicos "higienistas" y legisladores socialistas. Esa lucha consistía en extraer la administración de hospitales y hospicios de las manos de la Sociedad de Beneficencia y de Congregaciones Religiosas. Sólo con la llegada del Peronismo al poder, en 1948 la "honorable" Sociedad de Beneficencia fue estatizada y su actividad reemplaza por la ayuda peronista de la Fundación "Eva Perón" (Ferioli 1990).

10 Con esta palabra las voluntarias aluden a los/as personas que ostentan un título universitario de licenciados/as en: Trabajo Social (llamados/as asistentes sociales o visitadoras), Psicología, Sociología o Antropología. En general, aunque no siempre, las licenciadas están asociadas a oficinas de asistencia estatal.

11 Para Auyero (2001) esta argumentación nativa constituiría la distinción fundamental entre la acción caritativa de una voluntaria de Caritas y la "mediación política" de las "referentes" peronistas en una villa ubicada en el Gran Buenos Aires. Mientras para las referentes "la distribución de bienes y servicios es presentada como un elemento que depende de su reelección o nombramiento", para las voluntarias de Caritas de la parroquia de la Villa -argumenta Auyero- "hay una disociación explícita entre los bienes distribuidos y la persona a cargo de la distribución" (Ibid.: 161). En lugar de problematizar la naturaleza de esta "disociación" y el sentido que asume en la práctica caritativa de las voluntarias, Auyero considera a esta distinción nativa como principio explicativo de la misma. Este es uno de los procedimientos por medio de los cuales los supuestos constitutivos de la identidad del voluntariado adquieren su carácter naturalizado y su poderosa fuerza legitimadora.

12 Aquí la idea nativa de política está vinculada a individuo egoísta que busca en sus relaciones con otros individuos su propio beneficio. beneficio propio implica la expropiación de un recurso o bien propiedad de otro individuo. Esta acción suele ser llevada acabo por la persona "política" por medio de la violencia, concebida como enfrentamientos abiertos y públicos.

13 Ver un tratamiento disciplinar sobre estas opciones, que se pretenden mutuamente excluyentes, en Alayón, 1989.

14 El estado institucionaliza a través de la reforma de la Constitución, en 1949, nuevas reivindicaciones en materia social. Produce un cuerpo jurídico sin precedentes en materia de legislación laboral y previsión social. Concentra y unifica en su esfera burocrática las entidades 
ocupadas de la "Asistencia Pública", "Administración Sanitaria", "Departamento Nacional de Higiene", la Sociedad de Beneficencia. De este modo el estado crea la Dirección Nacional de Asistencia Social, encuadrada dentro del Ministerio de Trabajo y Previsión y la Secretaría de Salud Pública. (Passanante 1987: 125-135).

15 En ese contexto histórico la Fundación “Eva Perón” intentó resignificar la ayuda social, oponiéndola a "la beneficencia o la caridad de los ricos". Según la Presidenta de la Fundación, Eva Perón, la ayuda era estrictamente justicia para el pueblo (Perón 1951). Operando sobre este poderoso campo, Evita, la esposa del presidente de la Nación, fue instituida por el Parlamento en 1952 como la "Jefa Espiritual de la Nación". Masson 1999; Auyero 2001, se ocupan de estos aspectos simbólicos en contextos de militancia política de mujeres y política social.

16 Ver este aspecto de la relación voluntaria-beneficiaria en Zapata (2003).

17 En este sentido la relación entre voluntaria y chica no difiere en su naturaleza de la relación que traban entre sí asistente social estatal y voluntaria. Ambas son concebidas como relaciones personales basadas en el tiempo y en la confianza construida a través de las ayudas y obligaciones mutuamente, aunque desigualmente, pautadas.

18 Beatriz Heredia, problematizando el sentido de la política en las comunidades campesinas de Brasil, desarrolla el significado de la noción ayuda señalando que designa "tanto un bien o un favor venido de un candidato político o alguien influyente (...) En todos los casos, la ayuda recibida supone una retribución, que, por lo tanto, tiene implicaciones diferentes" (1996: 63-64). Para la autora toda ayuda supone para quién la recibe una obligación, una deuda que debe ser retribuida (Ibid.: 62).

19 Cuando uso la categoría "formas de dominación" no aludo al ejercicio consciente, deseado y maquiavélico del poder por parte de los agentes en cuestión. Las sociedades basadas en el principio de integración redistributivo suponen una forma de ejercicio de la dominación, no cuestionada ni experimentada como forma de expropiación, basada en el derecho que se arroga el soberano de concentrar, por medio de la apropiación, y redistribuir las riquezas socialmente producidas dentro de su esfera de influencia. Esta forma de apropiación no descarta el pago de tributos por parte de los súbditos al soberano, tributo que puede ser acumulado o atesorado como riqueza de orden personal, familiar, estatal, etc. Sobre este particular ver a Karl Polanyi (1957).

20 Sigo aquí las ideas de Bourdieu (1996) respecto de la economía del don y las formas de dominación simbólicas que ella supone.

21 La categoría "lujuria" no es usada aquí en su ordinario sentido sexual, sino que refiere al uso suntuario que caracteriza a determinados bienes. Para Appadurai los bienes "lujuriosos" no son mercancías que responden a una necesidad determinada, constituyen más bien un registro de consumo que distingue a quienes los practican. Los signos que caracterizan el consumo de bienes lujuriosos son: la restricción de su consumo a determinadas elites; la complejidad de su adquisición; la virtuosidad semiótica capaz de cifrar multiplicidad de sentidos; el conocimiento especializado como prerrequisito que demanda la adquisición y la práctica de este registro de consumo; y el alto grado de vinculación entre la adquisición de estos bienes y el cuerpo, la persona y la personalidad que los consume. La voluntaria está orientada hacia esos bienes lujuriosos, los programas sociales del estado, que suponen ejercer autoridad sobre determinados grupos sociales. 


\section{REFERÊNCIAS BIBLIOGRÁFICAS}

ALAYÓN, N. 1980. Historia del Trabajo Social en Argentina. Buenos Aires: Espacio Editorial.

Hvmanitas

1989. Asistencia y Asistencialismo: pobres controlados o erradicación de la pobreza?. Buenos Aires: Espacio

APPADURAI, Arjun. 1986. "Introduction: commodities and the politics of value". In: Appadurai, A. (ed.) The Social Life of Things: commodities in cultural perspective. Cambridge: Cambridge University Press.

AUYERO, J. 2001. La política de los pobres: Las prácticas clientelísticas del peronismo. Buenos Aires: Manantial.

BOURDIEU, P. 1996. “Marginalia. Algumas notas adicionais sobre o dom”. Mana 2 (2): 7-20.

DOUGLAS, M. 1990. “Forewords: No free gifts" In: Mauss, M. The gift: the form and reason for exchange in archaic societies. New York: W. W. Norton.

FERIOLI, N. 1990. La Fundación Eva Perón/2. Buenos Aires: CEAL.

GOLBERT, L. 1992. “La asistencia alimentaria: un nuevo problema para los argentinos” In: Lumi, S.; Golbert, L.; Tenti Fanfani, E. (orgs.) La mano izquierda del Estado: la asistencia social según los beneficiarios. Buenos Aires: Miño Dávila Editores/CIEPP

GRASSI, E. 1996. “Vivir en la Villa. Donde está la diferencia? In: Grassi, E. (org.) Las cosas del poder: acerca de/ estado, la política y la vida cotidiana, Buenos Aires: Espacio Editorial.

HEREDIA, B. 1996. “Política, Família, comunidade", In: Palmeira M.; Goldman M. (orgs): Antropología, voto e representação política. Rio de Janeiro: Contracapa.

ISUANI, E. 1990. “Bismark o Keynes ¿Quién es el culpable?: Notas sobre la crisis de acumulación”, In: Isuani, E.; Lo Vuolo, R. Y Tenti Fanfani, E. (orgs.) El Estado Benefactor, un paradigma en crisis. Buenos Aires: Ciepp/Miño y Dávila.

1992 “Política Social y Dinámica Política en América Latina” Desarrollo Económico 32 (125): 107-118.

KOPYTOFF, I. 1986. "The cultural biography of things: commoditization as process" In: Appadurai, A. (ed.) The social life of things: commodities in cultural perspective. Cambridge: Cambridge University Press.

LO VUOLO, R.; BARBEITO, A 1998. La Nueva Oscuridad de la Política Social: del estado Populista al Neoconservador. Buenos Aires: Miño y Dávila/Ciepp.

LO VUOLO, R.; BARBEITO, A.; PAUTASSI, L.; RODRÍGUEZ, C. 1999. La pobreza de la política contra la pobreza. Buenos Aires: Miño y Dávila/Ciepp.

LUMI, S.; GOLBERT, L.; TENTI FANFANI, E. 1992. La Mano izquierda del Estado: la asistencia social según los beneficiarios. Buenos Aires: Miño Dávila Editores/ Ciepp.

MASSON, L. 1999. Despolitizando la Política. Mujeres y Política Social en la Provincia de Buenos Aires, MN/ PPGAS/ UFRJ, Dissertação de Mestrado, Rio de Janeiro.

MAUSS, M. 1979. “Ensayo sobre los Dones. Razón y forma del cambio en las sociedades primitivas". In: Mauss, M. Sociología y Antropología. Madrid: Editorial Tecnos. 
OSZLAK, O. \& O'DONNELL, G. 1995. “Estado y políticas estatales en América Latina: hacia una estrategia de investigación". Redes, revista de estudios sociales de la ciencia, 4 (2): 98-128.

PASSANANTE, S. 1987. Pobreza y Acción Social en la Historia Argentina. Buenos Aires: Hvmanitas.

PERÓN, E. 1951. La Razón de mi Vida. Buenos Aires: Editorial Peuser.

PIGNA, A. 1983. "Caridad", Diccionario de Espiritualidad. T. I Abad/Esperanza, dirigido por Ermanno Ancilli, Barcelona: Editorial Herder.

POLANYI, K. 1957. “The Economy as an Institued Process", In: Polanyi, K. Et. Al. Trade and Market in the Early Empires, New York: The Free Press.

RECALDE, H. 1991. Beneficencia, asistencialismo estatal y previsión social/1. Buenos Aires: CEAL.

RODRíGUEZ, L. 2001. “De Clientas y Patronas: Etnografía de una organización de mujeres” Avá. Revista de Antropología. 3: 107- 119.

SAHLINS, M 1983. Economía de la Edad de Piedra. Madrid: Akal Editor.

ZAPATA, L. 2003. La Mano que Acaricia la Pobreza: economía y política del voluntariado y de los beneficiarios de Caritas de una parroquia católica marplatense. Dissertação de mestrado. Programa de Pós-graduação em Antropología Social (PPAS), Univesidad Nacional de Misiones (UNaM), Posadas, Argentina. 
Una antropología de la gratuidad: prácticas caritativas y políticas de asistencia social en la Argentina RESUMEN

El presente articulo analiza las prácticas de caridad que desarrollan un conjunto de agentes sociales definidos como "voluntarias de Caritas" y analiza la asistencia social del estado, que se materializa en programas de "ayuda social" que ejecutan esas voluntarias, en una parroquia católica de una ciudad media de la Argentina. A diferencia de lo que proponen los enfoques estatalistas sobre el fenómeno de asistencia social, aquí propongo que la caridad y la asistencia social son hechos estructuralmente asociados y que se han desarrollado como los polos opuestos alrededor del fenómeno de la circulación gratuita de objetos. A través de la descripción etnográfica de la vida cotidiana de la organización caritativa por excelencia de la Argentina, Caritas, la de sus agentes, las voluntarias, y de los programas sociales que allí se desarrollan, pretendo mostrar, desde el punto de vista de las voluntarias, la conflictividad cultural que provocan los fenómenos ligados a la gratuidad, lo cual demanda una antropología especialmente referida a estos fenomenos.

PALABRAS-CLAVE: asistencia social, gratuidad, organizaciones de voluntariado.

\section{An Anthropology of Gratuitousness: charity practices and social assistance policies in Argentine}

\section{ABSTRACT}

This papers analyzes charity practices developed by a group of social agents that define themselves as "Charity volunteers" as well as social assistance practices of the state, that materialize themselves in programs of "social help" lead by these volunteers in a Catholic parish of a medium city in Argentine. In contrast with "state oriented" ("estatalistas") approaches on the problem of social assistance, it is proposed here that charity and social assistance are structurally related facts and that they have developed themselves as opposite poles in relation to the phenomenon of free flow of things. In other words, charity and social assistance shape one type of social fact that rely on the principle that labels specific objects as free and as a consequence request an attitude towards them: the elimination of individual interest. The ambiguities of meaning attached to the phenomena framed within the logic of the gratuitousness often become "misunderstandings" and "double truths", which suppose permanent conflicts attached to charity and social assistance. Through ethnographic description of everyday routine of the mayor charity organization of Argentine, Caritas, of their agents, volunteers, and of the social programs it develops, I aim to show, from the point of view of the volunteers, the cultural conflicts that spur from phenomena attached to gratuitousness, which demand an anthropology that specifically refers to these social facts.

KEY WORDS: social assistance, gratuitousness, volunteering organizations. 